\title{
Los Tratados Bilaterales de Inversión desde la perspectiva de la Convención de Viena de Derecho de los Tratados: un camino hacia la "defragmentación" del Derecho Internacional
}

Bilateral Investment Treaties from the perspective

of the Vienna Convention on the Law of Treaties: a path towards the "defragmentation" of International Law

Autores: Agustina Vazquez, Natacha M. Marcote, Juan E. Osorio DOI: https://doi.org/10.25058/1794600X.1907

\footnotetext{
Ś MISIÓN JURÍDICA A
} 


\title{
LOS TRATADOS BILATERALES DE INVERSIÓN DESDE LA PERSPECTIVA DE LA CONVENCIÓN DE VIENA DE DERECHO DE LOS TRATADOS: UN CAMINO HACIA LA "DEFRAGMENTACIÓN" DEL DERECHO INTERNACIONAL*
}

\author{
Bilateral Investment Treaties from the perspective of the \\ Vienna Convention on the Law of Treaties: a path towards the \\ "defragmentation" of International Law \\ Tratados bilaterais de investimento na perspectiva da \\ Convenção de Viena sobre o Direito dos Tratados: um caminho \\ para a "desfragmentação" do Direito Internacional
}

\author{
Agustina Vazquez ${ }^{\text {a }}$ \\ avazquez@uflouniversidad.edu.ar
}

Natacha M. Marcote ${ }^{b}$ natachamarcote@live.com.ar

Juan E. Osorio ${ }^{c}$ jeosorio9@gmail.com

\footnotetext{
Fecha de recepción: 27 de septiembre de 2020 Fecha de revisión: 28 de octubre de 2020 Fecha de aceptación: 1 de diciembre de 2020
}

\section{RESUMEN}

La Convención de Viena sobre el Derecho de los Tratados propone el mecanismo consensuado por los Estados para la interpretación de los tratados internacionales. Los denominados TBI (Tratados Bilaterales de Inversión), son ejemplo y, específicos del Derecho Internacional de

\footnotetext{
*Artículo de reflexión.

a. Abogada (UBA) Diploma en Políticas Públicas (UDESA-George Washington University) Candidata a especialista en Docencia Universitaria (UFLO). Magister en Desarrollo y Derecho Internacional (University of London). Profesora de Derecho Internacional (UBA UFLO UCA UCES) y de Sociología Jurídica - Metodología de la Investigación (UBA UP). Investigadora externa (Universidad Católica de Córdoba). Directora de los proyectos de Investigación "¿CIADI en crisis?" y "Empresas y Derechos Humanos", bajo la programación científica de la Universidad de Flores. Visiting scholar en Florida International University (2019) Fellow RCIL Latin America and the Caribbean de las Naciones Unidas. (2019). Agradezco al Dr. Luis Castillo Argañarás sus aportes a la discusión de un borrador previo de este trabajo.

b. Abogada (UFLO). Investigadora del proyecto “¿CIADI en crisis?” bajo la programación científica de la Universidad de Flores.

c. Licenciado en Ciencia Política (UBA). Abogado (UFLO). Docente (UBA UFLO) Investigador del proyecto “CIADI en crisis?” bajo la programación científica de la Universidad de Flores.
} 
las Inversiones. Sin embargo, dentro de esta rama del Derecho Internacional, perduran inquietudes acerca de su correspondencia o no con la aplicación del denominado "tratado de los tratados"; e incentivadas desde la corriente impulsada principalmente por los "practicantes", árbitros o representantes de las partes, la forma en la que se han interpretado distintos tratados en materia de inversión, expone las tensiones de un Derecho Internacional fragmentado. ¿Quién ha de interpretarlos? ¿Bajo qué reglas?

Este trabajo propone: en primer término, abordar la génesis y evolución del Derecho Internacional de las Inversiones; en un segundo término, su caracterización como ejemplo de fragmentación sustantiva del Derecho Internacional; a efectos de abordar en tercer término, la interpretación conforme a las reglas de la Convención de Viena de Derecho de los Tratados entre Estados como una herramienta solucionadora del dilema presentado. La conclusión se adhiere a éste último punto, entendiendo tal instrumento como el único dentro de Derecho Internacional General que aboga por la interpretación armónica y la integración sistemática. Su consecuencia, daría una creciente seguridad jurídica -escenario favorable para los inversores-, y un mayor respeto por la voluntad de los Estados, creadores de la norma internacional en pugna.

\section{PALABRAS CLAVE}

Interpretación; tratados internacionales; Derecho Internacional; fragmentación; inversiones.

\section{ABSTRACT}

The Vienna Convention on the Law of Treaties proposes the mechanism agreed by the States for the interpretation of international treaties. The denominated Bilateral Investment Treaties (BITs) are a specific example of the International Investment Law. Nevertheless. within this branch of International Law doubts about its correspondence with the application of the "treaty of treaties" still persist and encouraged by the trend mainly promoted by the "practitioners", arbitrators or representatives of the parties, the way in which different treaties on investment matters have been construed expose the tensions of a fragmented International Law. Who has to interpret them? Under which rules? This article proposes, firstly, to tackle the genesis and evolution of the International Investment Law; secondly, its characterization as an example of the sustantive fragmentation of International Law, in order to address thirdly the interpretation according to the rules of the Vienna Convention on the Law of Treaties between States as a tool to solve the dilemma described. The conclusion follows the last point, understanding this instrument as the only one among the General International Law that advocates for a harmonious interpretation and a systematic integration.

Consequently, it would provide an increasing legal certainty -a favorable scenario for investorsand a greater respect for the will of the States that created the international norms in dispute.

\section{KEY WORDS}

Interpretation; international treaties; International Law; fragmentation; investments.

\section{RESUMO}

A Convenção de Viena sobre o Direito dos Tratados propõe o mecanismo acordado pelos Estados para a interpretação dos tratados internacionais. Os chamados BITs (Tratados Bilaterais de Investimentos) são um exemplo e são específicos do Direito Internacional de Investimentos. No entanto, dentro deste ramo do Direito Internacional, permanecem as preocupações sobre sua correspondência ou não com a aplicação do chamado "tratado de tratados"; e estimulada a partir da corrente promovida principalmente pelos "praticantes", árbitros ou representantes das partes, a forma como diferentes tratados de investimentos têm sido interpretados, expõe as tensões de um Direito Internacional fragmentado. Quem deve interpretá-los? Sob quais regras?

Este trabalho propõe: primeiro, abordar a gênese e a evolução do Direito Internacional de Investimento; em segundo lugar, sua caracterização como exemplo de fragmentação substantiva do Direito Internacional; a fim de abordar, em terceiro lugar, a interpretação de acordo com as regras da Convenção de Viena sobre o Direito dos Tratados entre Estados como instrumento para a solução do dilema apresentado. A conclusão vai ao encontro deste 
último ponto, entendendo tal instrumento como o único do Direito Internacional Geral que preconiza a interpretação harmoniosa e a integração sistemática. Seu desdobramento daria uma crescente segurança jurídica - cenário favorável aos investidores - e maior respeito à vontade dos Estados, criadores da norma internacional em conflito.

\section{PALAVRAS-CHAVE}

Interpretação; tratados internacionais; Direito internacional; fragmentação; investimentos.

\section{INTRODUCCIÓN}

El presente texto se inscribe en el marco de la investigación relativa a la crisis del CIADI, la cual pretende abordar la actual situación del sistema de resolución de controversias de carácter arbitral, a cargo del Centro Internacional de Arreglo de Diferencias Relativas a Inversiones (comúnmente denominado CIADI), desde la concepción del Derecho Internacional Público fragmentado.

Uno de los rasgos distintivos de los procedimientos arbitrales instituidos en virtud del Convenio del CIADI reside en que el Centro, a diferencia de otras instituciones arbitrales, es una organización internacional. Para ello, de conformidad con el llamado principio de especialidad (Henry Schermers \& Niels Blokker, 1995), las funciones del Centro se rigen por su tratado constitutivo, el Convenio del CIADI, que, como un tratado internacional, no puede ser modificado por la voluntad de las partes contendientes.

El objetivo del presente trabajo es abordar la fragmentación en el Derecho Internacional público a modo de elemento de diagnóstico de la crisis vivenciada en la jurisdicción del CIADI, la relación entre el Derecho Internacional General y la rama específica. Se propondrá la interpretación de tratados, conforme a las reglas de la Convención de Viena de Derecho de los Tratados (CVDT, en adelante) como una herramienta que convoque a una interpretación armónica e integración sistemática. Su consecuencia, se traduciría en una creciente seguridad jurídica -escenario favorable para los inversores-, y en un mayor respeto por la voluntad de los Estados, creadores de la norma internacional en pugna.

\section{EL DERECHO INTERNACIONAL DE LAS INVERSIONES}

Antes de la Segunda Guerra Mundial, la protección de la inversión extranjera directa (FDI en adelante, por sus conocidas siglas en inglés) no solía ser una preocupación en los acuerdos internacionales. La mayoría de los acuerdos económicos internacionales tenían por objetivo establecer relaciones comerciales, aunque estos acuerdos a veces incluían disposiciones sobre la protección de la propiedad de los nacionales de un Estado en el territorio de otro.

Los Estados Unidos, por ejemplo, ya en el siglo XVIII comenzaron a concluir tratados bilaterales de "Amistad, Comercio y Navegación" (FCN, por sus siglas en inglés), cuyo propósito era establecer relaciones comerciales con sus socios en los tratados (Walker Jr, 1957:810). Estos tratados incluían disposiciones que garantizaban "Protección especial" o "protección total y perfecta" a la propiedad de los nacionales, en territorio extranjero. También exigieron el pago de una indemnización por expropiación ${ }^{1}$ que se garantizaba a los nacionales de una de las partes de la nación más favorecida (NMF) $\mathrm{y}$ un trato nacional con respecto al derecho a participar en ciertas actividades comerciales en el territorio de la otra parte (Sullivan, 2009:65-66) Ocasionalmente, incluso proporcionaron servicios limitados de protección para las transferencias de divisas $^{2}$. El objetivo era proteger la propiedad, en lugar de la inversión.

La principal fuente normativa para la protección de las existencias de inversión internacional, hasta fines del siglo XIX, era la costumbre. Ésta, obligaba a los países receptores de una inversión a darle un trato conforme a un estándar mínimo internacional (Muchlinski, Ortino, \& Schreuer, 2008:200).Empero, la protección que ofrecía la regulación mediante el derecho internacional consuetudinario, resultó inadecuada para las mayores demandas que

1. Ver el Tratado de Amistad, Comercio y Navegación, Estados Unidos - Congo, suscripto el 24 junio de 1891, artículo 3.

Tratado de Amistad, Comercio y Privilegios Consulares, Estados Unidos - El Salvador, suscripto el 6 de diciembre de 1870 artículo 29.

2. Ver al respecto el Tratado General de Amistad, Comercio y Navegación, Estados Unidos - Yugoslavia, suscripto el 14.10.1881, artículo 3. 
presentaban los inversores (Muchlinski, et al, 2008: 250).

Los países latinoamericanos se adhirieron a la doctrina de Calvo, según la cual los inversores extranjeros solo tenían derecho a recibir un tratamiento análogo al que el país anfitrión le brindaba a sus propios inversores (Shea, 1955 y Cremades, 2004). Por su parte, persistía la falta de consenso dentro de la comunidad internacional respecto del contenido del estándar y se lo consideraba poco exigente con los Estados receptores de la inversión (Wythes, 2010).

Por su parte, la ausencia generalizada de un mecanismo independiente para que los inversores reclamasen respecto de sus inversiones, presentaba un complejo escenario frente a los casos de expropiación (Potestà, 2013:90). Inicialmente los reclamos se vehiculizaban mediante la protección diplomática, mecanismo por el cual el país de un nacional lesionado asume el reclamo del nacional como propio y lo presenta contra el país que ha lesionado al nacional.

Estos reclamos pueden ejercerse cuando la violación que sirve de causa resulta de la ruptura de una obligación del derecho internacional por parte del gobierno extranjero. Esta práctica, también llamada "esponsal", es un ejercicio de protección diplomática. Sin embargo, su poco ejercicio resulta un remedio insatisfactorio por varias razones: en primer lugar, el país del nacional no tiene la obligación de tomar todos los reclamos. Debiendo elegir entre priorizar la relación con otro Estado o proteger la inversión de su nacional, la disyuntiva muchas veces resulta compleja. En segundo lugar, y una vez que el inversor haya agotado los recursos jurídicos disponibles bajo la jurisdicción del Estado receptor, el Estado de nacionalidad del inversor asume la titularidad del reclamo. El inversor pierde totalmente el control sobre su reclamo y el Estado reclamante tiene derecho a resolver el reclamo en los términos que desee. Al respecto, Whiteman (1967) señala que, como la adhesión es esencialmente un proceso diplomático, no hay garantía de que el país anfitrión acepte resolver el reclamo en ninguno de los términos que se negocian a nivel de las relaciones internacionales.

Durante el siglo XIX, los Estados Unidos, por ejemplo, ejercieron una fuerte influencia sobre los países latinoamericanos para que, éstos, aceptasen periódicamente la presentación de reclamos en representación de sus nacionales, tramitando más de 40 en menos de 10 años de acuerdo con Summers (1972).

Como alternativa a la diplomacia, las naciones a veces utilizaron la fuerza militar para proteger las inversiones extranjeras, y en tal sentido se inscribe la Doctrina Monroe, que, por ejemplo, autorizó explícitamente el uso de la fuerza por parte de las tropas estadounidenses en el hemisferio occidental para cobrar deudas con ciudadanos estadounidenses (Rappaport, 1975)

El rechazo de América Latina a las doctrinas belicistas como respuesta a los reclamos económicos, propició la llegada del arbitraje inversor-Estado en la última parte del siglo $\mathrm{XX}$, lo que acarreó nuevos niveles de complejidad, incertidumbre y expansión sustantiva del Derecho Internacional, especialmente en lo relativo a la protección de las inversiones transnacionales. Su desarrollo a partir del siglo XX se sustanció en la continua proliferación de tratados bilaterales de inversión (TBI), así como la tendencia más reciente de los Estados a establecer acuerdos de libre comercio (TLC) que contienen capítulos de inversión.

Tal cambio ha llegado a casi todas las áreas del derecho, en especial a la práctica de los tratados de inversión. Los arbitrajes relativos a inversiones han abarcado la interpretación de obligaciones sustantivas y constituido una oportunidad para la participación de nuevos actores. En muchos laudos, los tribunales realizan un examen minucioso de las decisiones anteriores de tratados de inversión, conduciendo a la creación de lo que ahora se describe regularmente como una jurisprudencia de tratados de inversión (Lee, 2015:360). Sin embargo, la proliferación de la jurisprudencia de la materia no se ha dado de forma consensuada. Por el contrario, encontramos una pugna casi constante entre el derecho de las inversiones y el Derecho Internacional General, en el marco de su fragmentación, (Koskenniemi, 2006b; Nilsson, 2013).

\section{LA FRAGMENTACIÓN DEL DERECHO INTERNACIONAL DESDE EL DERECHO INTERNACIONAL DE LAS INVERSIONES}

El Derecho Internacional de las Inversiones ha sido una de las ramas del Derecho Internacional con mayor evolución en los últimos años, con 
especiales hitos -de índole contencioso- basados en el Derecho Internacional Económico. Sin embargo, gran parte de la discusión respecto de la fragmentación del Derecho Internacional ha dejado de lado este desarrollo y se ha centrado en la institucionalidad de la Organización Mundial de Comercio y del Centro Internacional de Arreglo de Diferencias Relativas a Inversiones, y su relación con los acuerdos de comercio internacional y otras ramas del Derecho Internacional, como los acuerdos ambientales internacionales o los tratados de Derechos Humanos.

Por mucho tiempo, la doctrina internacional discutió si los conflictos legales precisan de una definición acotada o amplia (Simma, 2009:265-270). Pero a partir del reporte de la "Fragmentación del Derecho Internacional", emitida por la Comisión de Derecho Internacional, encontramos que se ha popularizado una noción más amplia del conflicto internacional, que permite analizar mejor la interacción entre distintos tratados internacionales.

Un conflicto -señalan Werner, De Hoon, \& Galán (2017:150) interpretando a Koskenniemi (2006a)- existe no sólo cuando "Un Estado, parte de dos tratados, puede cumplir con las obligaciones contraídas bajo uno de ellos, y este cumplimiento, puede significar la violación del otro acuerdo", sino también cuando un tratado "frustra el cumplimiento del objeto y fin de otro tratado sin que haya una incompatibilidad estructural entre sus regulaciones".

Como ha indicado la Comisión de Derecho Internacional, la jurisdicción de la mayoría de los tribunales internacionales está limitada a tipos particulares de disputas o a temas específicos. Una jurisdicción limitada no implica una limitación del espectro de aplicación de la ley aplicable, ni que se vaya a hacer una interpretación acotada de los tratados; tal como ejemplifica el accionar de distintos tribunales arbitrales en materia de inversiones. Éstos, proveen un mayor margen de maniobra para inversores, árbitros y estados: tanto sus reglas procedimentales como las normas de fondos aplicables fueron redactadas en términos más amplios. Y el Tratado de Washington, junto con las reglas del CIADI, conforman la más utilizada lex arbitri en materia de inversiones (van Aaken, 2008: 500). En su artículo 42, dicho tratado señala que ha de aplicarse "Derecho Internacional" para la resolución de controversias internacionales, no confinando la ley sustantiva al Derecho Internacional de las Inversiones:

\section{Artículo 42}

(1) El Tribunal decidirá la diferencia de acuerdo con las normas de derecho acordadas por las partes. A falta de acuerdo, el Tribunal aplicará la legislación del Estado que sea parte en la diferencia, incluyendo sus normas de derecho internacional privado, y aquellas normas de derecho internacional que pudieren ser aplicables.

Del mismo modo, la normativa sustantiva -acuerdos internacionales de inversióngeneralmente explicitan que los tribunales deben considerar el Derecho Internacional aplicable, (van Aaken, 2008:300). Los tribunales internacionales pueden, entonces, resolver sobre cuestiones no relativas a Derecho Internacional de las Inversiones, así como efectuar determinación de hechos. Así, la ventana de posibilidades para aplicar el derecho relativo a las controversias internacionales se expande; y lo mismo sucede con la discrecionalidad de los tribunales arbitrales que han de resolver controversias entre Estados e inversores.

Las conexiones entre el Derecho de las Inversiones y otras áreas del Derecho Internacional son múltiples. Tomemos la siguiente situación:

Un estado regula la emisión de gases basándose en un acuerdo ambiental multilateral. A su vez, ha acordado un acuerdo con un inversor que blinda a este último de cambios regulatorios (por ejemplo, contratos suscriptos entre un Estado y un inversor, que contengan una cláusula de estabilización). La posibilidad de conflicto es alta.

Las inversiones, especialmente en materia de recursos naturales, suelen traducirse en actividades económicas de fuertes impactos ambientales. Los conflictos entre normas que protegen una inversión y las que protegen al medio ambiente son usuales, pero no los únicos que pueden sucederse. También pueden verse afectados, por ejemplo, distintos derechos humanos de los pobladores cercanos a la explotación de esos recursos naturales, como suelen verse afectados los derechos de comunidades originarias o de minorías étnicas. 
El mismo funcionamiento de una explotación de recursos naturales puede involucrar, en sus operaciones, un esquema de corrupción, sobornos y fraude, lo cual no sólo está regulado por la Convención de las Naciones Unidas contra la Corrupción, sino por distintos acuerdos regionales sobre la materia.

Presumiblemente, no todos los inversores recurrirán a una instancia internacional si su inversión se ve afectada, pero varios, sí lo harán.

La fragmentación, entonces, nos presenta el siguiente desafío: ¿qué reglas aplicar? ¿cómo hacer para que no coalicionen?

Antes de resolver cualquier problema legal, resulta necesario determinar qué ley se aplicará para resolver el conflicto, y sobre este punto se puede trazar una diferencia entre las controversias que se administran en el seno de la OMC y aquellas bajo auspicio del CIADI: en las primeras, Petersmann (2006: 280) explica que la jurisprudencia del sistema de solución de controversias de la OMC se refiere a "principios básicos del sistema multilateral de comercio" así como a principios generales de derecho, necesarios para la interpretación y balance de deberes y obligaciones específicos de los estados parte. Pero no sucede lo mismo en los tribunales arbitrales en materia de inversión, los cuales no refieren de forma uniforme a un grupo de principios.

A tales efectos, es importante trazar una distinción conceptual entre la "aplicación" de otras normas de Derecho Internacional (ya sean generales o especiales) y la interpretación de normas relativas al régimen de inversiones, las cuales han de interactuar con otros regímenes legales.

\section{TRATADOS BILATERALES DE INVERSIÓN: SU RELACIÓN CON OTRAS FUENTES DEL DERECHO INTERNACIONAL}

Las fuentes generadoras de normas que rigen la inversión extranjera se dividen en tres esferas superpuestas: la ley nacional, los contratos internacionales de inversión y los tratados de inversión. A efectos metodológicos, este trabajo se concentrará en la última fuente: la regulación convencional, de orden internacional, de las inversiones directas transnacionales.
Bajo estos acuerdos, los estados se proponen la promoción y protección de la inversión extranjera. Para inversores de un estado de origen que invierten en el territorio de otro estado anfitrión, se brindan protecciones especiales de conformidad con el derecho internacional. Los tratados de inversión adoptan distintas formas, incluyendo, la más común, los tratados bilaterales de inversión. El primero de su tipo, fue el TBI entre Alemania y Pakistán en 1959. Su contexto histórico es importante: el surgimiento de la regulación vía TBI se enmarco en el mundo post Segunda Guerra Mundial y el crecimiento de la descolonización que surgió rápidamente durante la década de 1960; mundo caracterizado por la tensión occidente-oriente y el avance el comunismo.

El contexto general de enorme incertidumbre política generada por la Guerra Fría, creó ansiedad y riesgo para los tenedores de capital privado en Occidente, y es una de las causas político-sociales que se tradujo en la regulación de las inversiones a nivel internacional, quizá como salvaguarda -o en búsqueda de una mayor estabilidad- de los cambios regulatorios que podían suceder en cualquier momento al cambiar de signo ideológico.

Desde 1959, se han firmado más de 2.750 tratados de este tipo; y se verifica un número creciente de capítulos en los acuerdos de libre comercio que incluyen disposiciones similares a las que se encuentran en los TBI.

Este desarrollo presenta nuevos desafíos, como la limitación a la potestad reguladora dentro de la cual las partes contratantes (Estados) pueden seguir sus políticas de desarrollo económico. Los TBI más recientes, señala Wellhausen (2016:5), han sido redactados con un enfoque más contemplativo del derecho al desarrollo; al mismo tiempo que se verifica un importante avance sobre las políticas públicas, en particular a través de, entre otras cosas, la inclusión de salvaguardas y excepciones relacionadas con la salud pública, la protección del medio ambiente y la seguridad nacional; como fuera interpretado en los casos de Pac Rim vs. El Salvador, Aguas del Tunari vs. Bolivia, Philip Morris vs. Uruguay o vs. Australia.

Por otra parte, la interacción de los TBI con otros acuerdos a diferentes niveles, incluidos los niveles bilateral, regional, plurilateral $\mathrm{y}$ 
multilateral, se vuelve más complicada. A modo de ejemplo, cabe recordarse el conflicto experimentado en el marco de la Unión Europea donde la convivencia de las normas de la Unión, no fue pacífica al interactuar con los TBI -vigentesfirmados entre distintos Estados que en la actualidad formaban parte del bloque económico. Tal fue el conflicto normativo, evidenciado en el caso Achmea y la Opinión 1/17 de la Corte de Justicia Europea -dentro del ámbito europeo- y en los casos arbitrales UP y CD Holdings vs. Hungría o AES vs. Hungría o Eureko vs. Eslovaquia - que recientemente, se alcanzó un acuerdo para que los Estados miembros que pongan fin a sus tratados bilaterales de inversión intra-UE, encontrándolos "desfasados e incompatibles con la legislación de la UE"3.

La interpretación en el régimen internacional de protección de las inversiones no es un asunto sencillo. Uno de los más reconocidos árbitros, Gary Born, planteó públicamente la pregunta: ¿Debemos interpretar los TBI de acuerdo con las pautas de la Convención de Derecho de los Tratados?, a la cual responde afirmativamente (2015).

\section{APLICACIÓN DE LA CONVENCIÓN DE VIENA DE DERECHO DE LOS TRATADOS}

La Convención de Viena contempla la existencia de tratados bilaterales; y en algunos casos sí plantea una regulación diferencial entre multilaterales y bilaterales, tal como el artículo 60 que distingue entre infracciones materiales de los tratados bilaterales y multilaterales ${ }^{4}$. Pero,

3. Al respecto, véanse los MEMO/15/5162 y MEMO/12/12. Así como el comunicado de prensa de la Comisión Europea disponible en https://ec.europa.eu/commission/presscorner/ detail/es/IP_15_5198

4. Al respecto, el artículo 60 del diferencia la terminación de un tratado o suspensión de su aplicación como consecuencia de su violación y dice: 1 . Una violación grave de un tratado bilateral por una de las partes facultará a la otra para alegar la violación como causa para dar por terminado el tratado o para suspender su aplicación total o parcialmente. 2. Una violación grave de un tratado multilateral por una de las partes facultará a) a las otras partes. procediendo por acuerdo unánime para suspender la aplicación del tratado total o parcialmente o darlo por terminado. Sea: i) en las relaciones entre ellas y el Estado autor de la violación: o ii) entre todas las partes; b) a una parte especialmente perjudicada por la violación para alegar ésta como causa para suspender la aplicación del tratado total o parcialmente en las relaciones entre ella y el Estado autor de la violación; c) a cualquier parte, que no sea el Estado autor de la violación, para alegar la violación como causa para suspender la aplicación del tratado total o parcialmente con respecto a sí misma, sí el tratado es de tal índole que una violación grave de sus disposiciones por una parte modifica radicalmente la situación de cada parte con respecto a la ejecución ulterior de en lo relativo a la interpretación de tratados artículos 31 y 32-, no hace ninguna diferencia a la clasificación según su número de partes signatarias. Tampoco distinguen entre un tratado y lo que algunos llaman un "régimen de tratado" (Salacuse, 2010:430).

El Artículo 31 prescribe la interpretación de buena fe, conforme al significado ordinario de las palabras del tratado. Éstas deben siempre interpretarse a la luz de su objeto y propósito. Estos últimos, están destinados a complementarse entre sí. Esta práctica, es usada en el ámbito del Derecho de las Inversiones.

La interpretación de un tratado, continúa la Convención de Viena, implica considerar el texto, preámbulo y anexos, así como cualquier acuerdo relacionado hecho entre las partes en relación con la conclusión del tratado, y cualquier instrumento hecho por una o más partes en relación con la conclusión del tratado y aceptado por las otras partes como un instrumento relacionado. Así mismo, el artículo 31.3 establece que, además, un intérprete considerará los acuerdos posteriores con respecto a la interpretación o aplicación del tratado, la práctica posterior en la aplicación del tratado y "cualquier norma pertinente de derecho internacional aplicable en las relaciones entre las partes".

Finalmente, el artículo 32 permite recurrir a medios de interpretación complementarios, incluido el trabajo preparatorio del tratado y las circunstancias de su celebración, para confirmar el significado alcanzado a través del proceso del artículo 31 o en casos de ambigüedad, oscuridad $o$ absurdo manifiesto.

Laird (2014) ha discutido junto con Andrea Bjorklund, Todd Weiler, Frédéric G. Sourgens y Borzu Sabahi acerca de si, sirven entonces, las reglas de interpretación que propone la Convención de Viena para el tema que aquí nos

sus obligaciones en virtud del tratado. 3. Para los efectos del presente artículo, constituirán violación grave de un tratado: a un rechazo del tratado no admitido por la presente Convención o b) la violación de una disposición esencial para la consecución del objeto o del fin del tratado. 4. Los precedentes párrafos se entenderán sin perjuicio de las disposiciones del tratado aplicables en caso de violación. 5. Lo previsto en los párrafos 1 a 3 no se aplicará a las disposiciones relativas a la protección de la persona humana contenidas en tratados de carácter humanitario, en particular a las disposiciones que prohíben toda forma de represalias con respecto a las personas protegidas por tales tratados. 
convoca; y hemos de dividir el espectro de las distintas posiciones en el siguiente orden:

Sourgens (2017: 155) plantea que la Convención de Viena debiera ser inaplicable por ser un tratado internacional, signado entre Estados, y que de acuerdo a las reglas del Derecho Internacional Público, no permite a otros sujetos de Derecho (como los individuos, o inversores en el Derecho de las Inversiones) ser parte. En particular, este autor entiende problemático que las empresas no puedan ser parte de la Convención de Viena; así como la interpretación de la figura del inversor como un "tercero" conforme al tratado de tratados.

En su texto Supernational Law, Sourgens, va más allá, al estudiar la asimetría del sistema de resolución de controversias y entiende que se está generando un ordenamiento jurídico mixto respecto a la regulación de las inversiones; uno que combina un Derecho Administrativo Global, Derecho Internacional Público, Derecho de la Integración y Derecho Internacional Privado (2017:156). En esta naciente nueva regulación, la interpretación no se haría conforme a las reglas de los tratados, ya que la misma circunscribe a los inversores a la figura de "terceros" y les confiere escasos derechos en el orden internacional, regulados por los artículos 34 a 37 de la CVDT.

Por su parte, Todd Weiler propone un enfoque histórico y pregunta si la Convención de Viena puede tomarse como "ley aplicable" para interpretar los TBI. Sus argumentos se concentran en gran medida a favor de la aplicación de la CVDT a los tratados bilaterales sobre inversiones, pero concede un puto interesante a la tesis de Sourgens: el enfoque de la Convención refleja las reglas de interpretación del derecho internacional consuetudinario, creada a partir de las acciones de los Estados. A su entender, dado que estas reglas se han aplicado de una manera increíblemente desigual, sería posible pensar en su no aplicación so pretexto de una "mayor seguridad jurídica" (Weiler, 2005).

Borzu Sabahi -desde su doble rol de docente y litigante en la materia- entiende que la Convención de Viena es una herramienta flexible, que claramente se enfrenta a desafíos coyunturales, tales como: la fragmentación sustantiva e institucional del Derecho Internacional; pero que sigue siendo el instrumento internacional que sirve para interpretar el Derecho Internacional de las Inversiones.

Creada desde una posición estadocéntrica, su texto refleja la voluntad de los Estados, del mismo modo que los tratados bilaterales de inversión: siguen siendo tratados signados entre Estados, por más que sean los inversores quienes los invocan para la defensa de sus inversiones.

Finalmente, Andrea K. Bjorklund, pregunta si se puede equiparar un tratado con un contrato. $\mathrm{Su}$ interrogante genera un análisis que recorre distintos tribunales internacionales, partiendo de la jurisdicción ratione materiae del viejo tribunal del NAFTA, el cual entiende que aplicará "las reglas del Derecho Internacional" para decidir los casos que le sean sometidos. También, recuerda que la Convención de Viena conjuga Derecho Internacional Consuetudinario así como Convencional y que ambas son fuentes creadoras de normas del Derecho Internacional, generadas por voluntad de los Estados.

Sin embargo, cuando presenta el posible caso de una disputa contractual entre un demandante y un Estado receptor de una inversión, no resulta tan claro si se ha de aplicar la Convención de Viena. Bjorklund entiende que sí "siempre y cuando los términos del contrato sean dictados por los términos del tratado".

Esta última tesitura, encuentra un desafío argumentativo: está en contra de las propias provisiones de la Convención de Viena de Derecho de los Tratados que en sus artículos primero y segundo indica su ámbito material de aplicación:

1. Alcance de la presente Convención. La presente Convención se aplica a los tratados entre Estados.

\section{Términos empleados.}

\section{Para los efectos de la presente Convención:}

a) se entiende por "tratado" un acuerdo internacional celebrado por escrito entre Estados y regido por el derecho internacional, ya conste en un instrumento único o en dos o más instrumentos conexos y cualquiera que sea su denominación particular; 
b) se entiende por "ratificación", "aceptación", "aprobación" y "adhesión", según el caso, el acto internacional así denominado por el cual un Estado hace constar en el ámbito internacional su consentimiento en obligarse por un tratado;

c) se entiende por "plenos poderes" un documento que emana de la autoridad competente de un Estado y por el que se designa a una o varias personas para representar al Estado en la negociación, la adopción o la autenticación del texto de un tratado, para expresar el consentimiento del Estado en obligarse por un tratado, o para ejecutar cualquier otro acto con respecto a un tratado;

d) se entiende por "reserva" una declaración unilateral, cualquiera que sea su enunciado o denominación, hecha por un Estado al firmar, ratificar, aceptar o aprobar un tratado o al adherirse a él, con objeto de excluir o modificar los efectos jurídicos de ciertas disposiciones del tratado en su aplicación a ese Estado;

e) se entiende por un "Estado negociador" un Estado que ha participado en la elaboración y adopción del texto del tratado;

f) se entiende por "Estado contratante" un Estado que ha consentido en obligarse por el tratado, haya o no entrado en vigor el tratado;

g) se entiende por "parte" un Estado que ha consentido en obligarse por el tratado y con respecto al cual el tratado está en vigor;

h) se entiende por "Tercer Estado" un Estado que no es parte en el tratado;

i) se entiende por "organización internacional" una organización intergubernamental.

II. Las disposiciones del párrafo I sobre los términos empleados en la presente Convención se entenderán sin perjuicio del empleo de esos términos o del sentido que se les pueda dar en el derecho interno de cualquier Estado.

Ampliar el mismo, es una flagrante violación al consentimiento de los Estados -creadores de Derecho Internacional- y significaría dotar a un sujeto de derecho privado, de un presunto ius tractum internacional.
Retomando el asunto de esta sección, debe plantearse que si bien un tribunal arbitral podría ampliar los conceptos de "contexto", "instrumento relacionado" y "trabajo preparatorio" para incorporar otras prácticas de tratados, tal razonamiento parecería violar el lenguaje y el propósito de la Convención de Viena.

Los artículos 31 y 32, sobre todo, incorporan el principio: las partes del tratado se obligan sólo en los términos de lo escrito en el texto. De ahí la necesidad en el Artículo 31.2.b de otras partes de aceptar los instrumentos hechos por una o más partes en relación con la celebración del tratado como "un instrumento relacionado con el tratado"5. Los tratados de inversión, al igual que los contratos en el orden doméstico, son expresiones de consentimiento.

El caso Alemanni vs. Argentina consideró, en su párrafo 304:

[...] Su tarea no consiste en determinar el régimen legal general aplicable a las disposiciones de este tipo, sino en decidir la cuestión muy específica destinada a establecer si Argentina ha prestado o no su consentimiento irrevocable al arbitraje en las circunstancias en que los demandantes han iniciado el arbitraje que nos ocupa. La cuestión se rige en su totalidad por el Artículo 8 del TBI, que contiene la oferta de arbitraje de ambos Estados parte en el tratado y que (como el tribunal de Ambiente Ufficio observa de manera pertinente1) "no marca una diferencia entre los requisitos 'obligatorios' y 'no obligatorios' así como entre requisitos previos 'jurisdiccionales', 'de admisibilidad' o 'procesales'

[...] El Convenio CIADI no puede interpretarse correctamente en el sentido de conceder alguna forma de consentimiento previo a arbitraje -ni conforme a sus propios términos ni, en particular, a la luz de las declaraciones categóricas contenidas, tanto en su Preámbulo [...] como en el Artículo 25(4), en virtud del cual la indicación por un Estado parte de los tipos de controversias que consideraría someter a la jurisdicción del Centro.

5. El artículo 31.2. b entiende que a efectos de la interpretación de un tratado, habrá de considerarse "todo instrumento formulado por una o más partes con motivo de la celebración del tratado y aceptado por las demás como instrumento referente al tratado". 
De ello se desprende inexorablemente que el consentimiento operativo necesario tiene que buscarse en otro lugar, y que, en el caso que nos ocupa, significa el Artículo 8 del TBI, que -a los ojos del Tribunal- se encuentra redactado precisamente con miras a dicho objetivo, en particular, en el segundo párrafo del Artículo 8(3), que reza lo siguiente: "A ese fin, y de conformidad con los términos de este Acuerdo, cada Parte Contratante otorga por el presente su consentimiento anticipado e irrevocable para que toda controversia pueda ser sometida al arbitraje". Esta frase despeja toda duda imaginable al establecer que el Artículo 8 es el que contiene el consentimiento permanente de cada Parte Contratante, como posible Estado demandado, al inicio de un arbitraje por parte de los inversores. La redacción establece con igual claridad que el consentimiento allí prestado es "de conformidad con los términos de este Acuerdo".

La interpretación efectuada por el tribunal arbitral en el caso citado, se corresponde a la aplicación de las cláusulas de interpretación de la Convención de Viena; empero, no todos los tribunales arbitrales han elegido este camino. Señala Weeramantry (2012) que muchos tribunales, en su lugar, basan su argumentación en las nociones de justicia, la equidad, eficiencia o la razonabilidad. Ésta práctica, se encuentra muy difundida y aceptada en el mundo del arbitraje de las inversiones y podría pensarse que es una forma implícita para no aplicar las reglas de la interpretación de la Convención de Viena.

Tomemos por ejemplo la noción de "trato justo y equitativo": su evolución ha sido jurisprudencial, y en los últimos 20 años, los distintos tribunales arbitrales se han preocupado más de aplicar el estándar citando su evolución jurisprudencial que de interpretar los alcances del estándar en el marco del tratado invocado en la contienda jurídica que les compete. Esto, ha resultado en laudos que han interpretado distintos tratados bilaterales de inversión aplicando estándares de la propia carta del NAFTA.

Si bien la jurisprudencia es una de las fuentes secundarias del Derecho Internacional y sirve para interpretar las normas provenientes de un tratado (Shaw, 2003), no podemos obviar que los tribunales de los casos Rumeli vs. Kazajstán, Parkerings vs. Lituania, El Paso Energy International Company vs. Argentina, Azinian vs.
México, Tecmed vs. México o el clásico Saluka vs. República Checa interpretan tratados distintos; y que, en la mayoría de ellos, el NAFTA resultaba ajeno.

A modo de conclusión parcial, resulta de lo anterior el siguiente cuestionamiento: resulta necesario que los tribunales arbitrales se planteen “ ¿Lo que estoy interpretando significa lo mismo en todos los tratados que dan la base a los precedentes que estoy citando?".Ésta pregunta es el resultado lógico de asumir una postura a favor de la uniformidad del Derecho Internacional, que reduzca los conflictos normativos de un Derecho Internacional fragmentado, tal como fuera reseñado en la sección 2 .

Cuando un tribunal ha resolver un caso, y decide relevar la jurisprudencia sobre el tema, no puede dejar de plantearse que el tratado que legitima su competencia, suele ser distinto que los tratados que han sido utilizados para interpretar los estándares en pugna.

Propiciar resoluciones arbitrales que se centren en la cita de precedentes, originados en distintos tratados, y no efectuar un análisis conforme al artículo 31 de la Convención de Viena, resulta contrario al Derecho Internacional Público General.

Cada tratado posee sus propios contextos, objetos, propósitos, textos, preámbulos, anexos, acuerdos relacionados, acuerdos posteriores, instrumentos relacionados y trabajos preparatorios, y los términos que se han de resolver, pueden ser distintos en cada tratado; distinto a la voluntad de los Estados contratantes.

\section{CONCLUSIONES}

Los tribunales arbitrales han navegado entre los principios legales y la realidad. Los principios receptados en las reglas de la Convención de Viena, y la noción de consentimiento, resultan siendo pivotes y soportes del Derecho Internacional.

El Derecho Internacional de las Inversiones no posee un único cuerpo legal, a diferencia del Derecho Internacional Económico en el marco del sistema multilateral de comercio. Sumado a la pluralidad de foros para el arbitrio de disputas, encontramos que hay una preocupante amplitud respecto de la ley que se vaya a utilizar para zanjar una controversia arbitral; la cual se inserta en los 
conflictos normativos descriptos por la Comisión de Derecho Internacional en su informe sobre la fragmentación del Derecho Internacional.

Un breve repaso jurisprudencial dentro del área del Derecho Internacional de las Inversiones nos muestra una fuerte reticencia a la aplicación de normas internacionales ajenas a la rama específica, tal como los casos de St. Elena vs. Costa Rica o SPP vs. Egipto. Sin embargo, también se advierte una preocupante tendencia de los tribunales arbitrales a efectuar decisiones basándose en precedentes y no conforme a las reglas de interpretación de los tratados, reglas de Derecho Internacional que resultan de aplicación a los conflictos que administran.

La "defragmentación" del Derecho Internacional conlleva a una interpretación armónica e integración sistemática. Su consecuencia, se traduciría en una creciente seguridad jurídica -escenario favorable para los inversores-, y en un mayor respeto por la voluntad de los Estados, creadores de la norma internacional en pugna.

\section{REFERENCIAS BIBLIOGRÁFICAS}

- Born, G. (2015). Should Investment Treaties Have Their Own Rules of Interpretation? Disponible en: http://arbitrationblog. kluwerarbitration.com/2015/02/03/ should-investment-treaties-have-theirown-rules-of-interpretation/

- Cremades, B. (2004). Disputes Arising Out of Foreign Direct Investment in Latin America: A New Look at the Calvo Doctrine and Other Jurisdictional Issues Texto. Dispute Resolution Journal, 59(2), 1-9.

- Koskenniemi, M. (2006a). Fragmentation of Internacional Law: Difficulties arising from the diversification and expansion of International Law. Report of the Study Group of the International Law Commission (Vol. A/CN.4/L.6). Disponible en https://legal. un.org/ilc/documentation/english/a_cn4_ 1682.pdf

- Koskenniemi, M. (2006b). Fragmentation of International Law: Difficulties arising from the diversifiation and expansion of International Law (Vol. A/CN.4/L.6). Nueva York. Disponible en: https://legal.un.org/ ilc/documentation/english/a_cn4_1682.pdf

- Laird, I. (2014). Is the Vienna Convention on the Law of Treaties Dead in BIT Arbitration?. Disponible en https://oxia.ouplaw.com/ page $/ 475$

- Lee, J. (2015). Resolving concerns of treaty shopping in international investment arbitration. Journal of International Dispute Settlement, 6(2), 355-379. https://doi. org/10.1093/jnlids/idv011

- Muchlinski, P., Ortino, F., \& Schreuer, C. (2008). The Oxford Handbook of International Investment Law. The Oxford Handbook of International Investment Law (1st ed.). Oxford University Press. https://doi.org/10.1093/ oxfordhb/9780199231386.001.0001

- Nilsson, A. O. (2013). Inconsistent Awards in Investment Treaty Arbitration: Is an Appeals Court Needed? Journal of International Arbitration, 30(5), 561-579.

- Petersmann, E.U. (2006). Justice as conflict resolution: Proliferation, fragmentation, and decentralization of dispute settlement in international trade. University of Pennsylvania Journal of International Law, 27, 273-300.

- Potestà, M. (2013). Legitimate expectations in investment treaty law: Understanding the roots and the limits of a controversial concept. ICSID Review, 28(1), 88-122. https://doi.org/10.1093/icsidreview/ sis034

- Rappaport, A. (1975). A History of American Diplomacy. Nueva York: Macmillan.

- Salacuse, J. (2010). The emerging 
global regime for investment. Harvard International Law Journal, 51(2), 427-473.

- Schermers, H. \& Blokker, N. (1995).

- Shaw, M. N. (2003). International law, fifth edition. International Law, Fifth Edition. $\quad$ https://doi.org/10.1017/ CB09781139051903

- Shea, D. (1955). The Calvo Clause: A problem of inter-American and international law and diplomacy. Minnesota: University of Minnesota Press.

- Simma, B. (2009). Universality of international law from the perspective of a practitioner. European Journal of International Law, 20(2), 265-297. https:// doi.org/10.1093/ejil/chp028

- Sourgens, F. (2017). Supernational Law. Vanderbilt Journal of Transnational Law, 50(1), 155-216. Disponible en http:// search.ebscohost.com/login.aspx?direct=tr ue \&db=aph\&AN=123462654\&amp;lang=ja $\&$ site $=$ ehost-live

- Sullivan, J. W. S. N. P. (2009). Do BITs Really Work?: An Evaluation of Bilateral Investment Treaties and their Grand Bargain. In The effect of treaties on foreign direct investment: bilateral investment treaties, double taxation treaties and investment flows (pp. 1-66). Cambridge: Cambridge University Press. https://doi.org/10.1093/acprof

- Summers, L. (1972). Arbitration and Latin America. California Western International Law Journal, 3(1), 7-17.

- van Aaken, A. (2008). Fragmentation of International Law: The Case of International Investment Law. Finnish Yearbook of International Law, 17, 91-130. Disponible en https://papers.ssrn.com/sol3/papers. cfm?abstract_id=1097529

- Walker Jr, H. (. (1957). Modern treaties of friendship, commerce and navigation. Minnesota Law Review, 42, 805-840.

- Weeramantry, J. R. (2012). Treaty interpretation in investment arbitration. Oxford: Oxford University Press.
- Weiler, T. (2005). International Law and Arbitration: Leading Cases from the ICSID, NAFTA, Bilateral Treaties and Customary International Law. Nueva York: Cameron May.

- Wellhausen, R. L. (2016). Recent trends in investor-state dispute settlement. Journal of International Dispute Settlement, 7(1), 117-135. https://doi.org/10.1093/jnlids/ idv038

- Werner, W., De Hoon, M., \& Galán, A. (2017). The law of international lawyers: Reading Martti Koskenniemi. The Law of International Lawyers: Reading Martti Koskenniemi. Cambridge: Cambridge University Press. https://doi.org/10.1017/9781108147620

- Whiteman, M. (1967). Digest of International Law (No. III). Washington DC.

- Wythes, A. (2010). Investor-state arbitrations: Can the fair and equitable treatment clause consider international human rights obligations? Leiden Journal of International Law, 23(1), 241-256. https:// doi.org/10.1017/S0922156509990409

\section{JURISPRUDENCIA CITADA:}

Achmea B.VS. vs. The Slovak Republic, UNCITRAL, PCA Case No. 2008-13 (formerly Eureko B.VS. vs. The Slovak Republic), decisión sobre jurisdicción del 26 de octubre del 2010. Disponible en https://www.italaw.com/ cases/documents/418

AES Summit Generation Limited and AESTisza Erömü Kft vs. The Republic of Hungary, ICSID Case No. ARB/07/22, laudo del 23 de septiembre del 2010. Disponible en https:// www.italaw.com/cases/193

Aguas del Tunari, S.A. vs. Republic of Bolivia, ICSID Case No. ARB $/ 02 / 3$, decisión sobre la jurisdicción del 21 de octubre del 2005. Disponible en https://investmentpolicy. unctad.org/investment-dispute-settlement/ 
cases/74/aguas-del-tunari-v-bolivia

Compañia del Desarrollo de Santa Elena S.A. vs. Republic of Costa Rica, ICSID Case No. ARB/96/1, laudo del 17 de febrero del 2000. Disponible en https://www.italaw.com/ cases/documents/3414

El Paso Energy International Company v. The Argentine Republic, laudo del 31 de octubre del 2011. Disponible en https://www.italaw. com/cases/documents/383

Pac Rim Cayman LLC vs. Republic of El Salvador, ICSID Case No. ARB/09/12, laudo del 14 de octubre del 2016. Disponible en https:// www.italaw.com/cases/783

Parkerings-Compagniet AS v. Republic of Lithuania, ICSID Case No. ARB/05/8, laudo del 11 de septiembre del 2007. Disponible en https://www.italaw.com/cases/812

Philip Morris Asia Limited vs. The Commonwealth of Australia, UNCITRAL, PCA Case No. 2012-12, laudo del 17 de diciembre del 2015. Disponible en https://www.italaw. com/cases/851

Philip Morris Brands Sàrl, Philip Morris Products S.A. and Abal Hermanos S.A. vs. Oriental Republic of Uruguay, ICSID Case No. ARB/10/7, laudo del 8 de julio del 2016. Disponible en https://www.italaw.com/ cases $/ 460$
Robert Azinian, Kenneth Davitian, \& Ellen Baca v. The United Mexican States, ICSID Case No. ARB (AF)/97/2, laudo del 1 de noviembre del 1999. Disponible en https://www.italaw.com/ cases/114

Rumeli Telekom A.S. and Telsim Mobil Telekomunikasyon Hizmetleri A.S. v. Republic of Kazakhstan, ICSID Case No. ARB/05/16, laudo del 29 de julio del 2008. Disponible en https://www.italaw.com/ cases/942

Saluka Investments B.V. v. The Czech Republic, UNCITRAL, laudo parcial del 17 de marzo del 2006. Disponible en https://www.italaw.com/ cases/961

Southern Pacific Properties (Middle East) Limited vs. Arab Republic of Egypt, ICSID Case No. ARB $/ 84 / 3$, laudo del 20 de mayo de 1992. Disponible en https://www.italaw.com/ cases $/ 3300$

Técnicas Medioambientales Tecmed, S.A. v. The United Mexican States, ICSID Case No. ARB (AF)/00/2, laudo del 29 de mayo del 2003. Disponible en https://www.italaw.com/ cases/1087

UP (formerly Le Chèque Déjeuner) and C.D Holding Internationale vs. Hungary, ICSID Case No. ARB/13/35, decisión sobre jurisdicción del 3 de marzo del 2016. Disponible en https:// www.italaw.com/cases/documents/6903 